\title{
Tipologi Potensi Kepariwisataan Desa Sekitar Candi Borobudur
}

\author{
Akbar Preambudi ${ }^{\text {a, } 1}$ \\ a Prodi Arsitektur Universitas Teknologi Yogyakarta, Fakultas Sains dan Teknologi, Jl. Glagahsari No. 63, D.I. Yogyakarta, \\ 55164 \\ 1 akbar.preambudi@gmail.com
}

\begin{tabular}{ll}
\hline Informasi artikel & ABSTRAK \\
\hline Sejarah artikel: & Desa sekitar Candi Borobudur memiliki banyak potensi kepariwisataan yang dirasa \\
Diterima & tenggelam akibat semua perhatian ditujukan ke Candi Borobudur. Pengelolaan \\
Revisi & Candi Borobudur dengan sistem bisnis yang berlebihan mengakibatkan persoalan \\
Dipublikasikan & kesejahteraan atau kemiskinan yang dialami oleh masyarakat di desa-desa sekitar \\
\hline Kata kunci: & Candi Borobudur. \\
Tipologi & Sehubungan dengan penentuan model pengembangan potensi obyek wisata, maka \\
Potensi kepariwisataan & dalam studi ini mengadopsi dinamika pengembangan pariwisata yang \\
Borobudur & dikemukakan oleh Miossec (Pearce I989). Model evolusi didasarkan pada empat \\
& faktor yang dapat mempengaruhi pengembangan, yaitu; (I) resort; (2) transport; \\
& (3) tourist behaviour; (4) attitudes of decision makers and population of receiving \\
& region. \\
& Tipologi desa sekitar Candi Borobudur dipetakan berdasarkan potensi \\
& kepariwisatan dengan cara menganalisis temuan-temuan di lapangan kemudian \\
dikompilasikan dengan teori maupun data lainnya. Tipologi potensi menghasilkan & \\
tipe desa berdasarkan teori Miossec.
\end{tabular}

Key word:

Typology

Tourism Potential

Borobudur

\section{ABSTRACT}

Tourism Potential Typology of The Villages Around Borobudur Temple. The villages around Borobudur Temple have many tourism potentials that feel drowned by all the attention devoted to Borobudur Temple. Management of Borobudur temple with excessive business systems resulted in prosperity or poverty problems experienced by the people in the villages around Borobudur.

In relation with the determination of the development potential model for tourism, then this study adopts the dynamics of tourism development proposed by Miossec (Pearce 1989). Evolutionary model is based on four factors that may affect the development, namely; (I) resort; (2) transport; (3) tourist behavior; (4) attitudes of decision makers and population of receiving region.

The typology of the villages around Borobudur mapped based on tourism potential by analyzing the the findings in the field and then compiled with the theory or the other data. Typology of the potential produce the type of villages based on Miossec theory.

Copyright $₫ 2020$ Universitas Widya Mataram Yogyakarta. All Right Reserved

\section{Pendahuluan}

Pengembangan obyek dan daya tarik pariwisata dipadukan dengan pengembangan jasa, sarana dan prasarana pariwisata seperti biro perjalanan, hotel, restoran, transportasi, toko souvenir, jasa konvensi, pemandu wisata, dan penukaran valuta asing. Dalam kegiatan pariwisata selalu melibatkan masyarakat, sehingga membawa berbagai dampak terhadap masyarakat setempat. Sektor industri pariwisata merupakan salah satu sektor yang terus menerus dilakukan oleh pemerintah secara nasional maupun global.

Desa sekitar Candi Borobudur memiliki banyak potensi kepariwisataan yang dirasa tenggelam akibat semua perhatian ditujukan ke Candi Borobudur. Pengelolaan Candi Borobudur dengan sistem bisnis yang berlebihan mengakibatkan persoalan kesejahteraan atau kemiskinan yang dialami oleh masyarakat di desa sekitar Candi Borobudur.

Meningkatnya kunjungan wisatawan ke masing-masing desa, sekaligus mengembangkan dan meningkatkan kesejahteraan masyarakat di kawasan Candi Borobudur karena desa wisata melibatkan secara aktif dan menyeluruh peran serta masyarakat. Ada beberapa desa yang mengalami perubahan 
terutama sejak wisatawan mulai masuk ke desa mereka. Namun demikian tidak semua desa mampu merespon kegiatan pariwisata secara cepat dan baik.

Pada penelitian ini adalah fokus kepada pemahaman tipologi potensi tiap desa di sekitar Candi Borobudur. Potensi Borobudur yang sangat besar menjadikan persoalan kesejahteraan atau kemiskinan yang dialami oleh masyarakat sekitar Candi Borobudur menjadi semakin serius. Hal tersebut terjadi karena kurangnya pengelolaan potensi wisata di desa sekitar Candi Borobudur. Partisipasi masyarakat dan stakeholder dalam proses pembentukan ruang desa wisata serta seberapa besar peran masyarakat dalam kegiatan pariwisata. Tingginya angka kunjungan wisatawan ke Borobudur tentunya diperlukan manajemen pengelolaan ruang kawasan sekitar Borobudur. Salah satunya dengan mendayagunakan desa sekitar Candi Borobudur untuk menciptakan pariwisata yang berdaya saing secara global baik dalam skill, kemampuan, dan inovasi, maka dibutuhkan perencanaan dan perancangan kawasan potensial di sekitar Candi Borobudur menjadi kawasan atraksi wisata.

\section{Metode}

Studi ini mengadopsi dinamika pengembangan pariwisata yang dikemukakan oleh Miossec (Pearce, 1989) dalam penentuan model pengembangan potensi obyek wisata (Lihat Gambar 1). Model evolusi didasarkan pada empat faktor yang dapat mempengaruhi pengembangan, yaitu; (1) resort; (2) transport; (3) tourist behaviour; (4) attitudes of decision makers and population of receiving region.

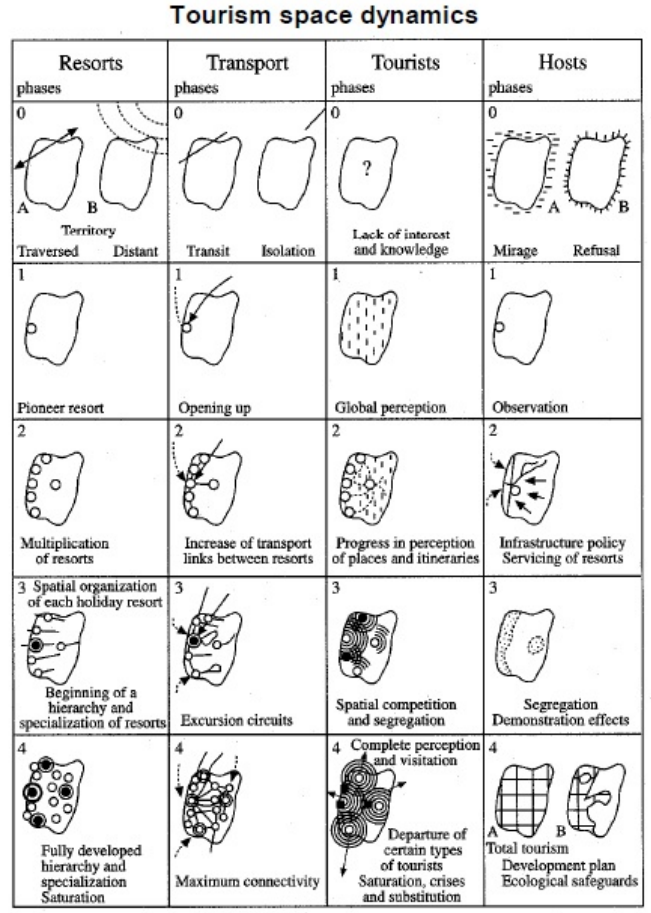

Gambar 1. Dinamika Pengembangan Pariwisata menurut Miossec

Model Miossec menyajikan beberapa aspek yang berguna. Pembangunan wilayah dalam ruang dan waktu. Gagasan ruang / waktu evolusi sangat penting baik dalam analisis proses masa lalu serta dalam perencanaan pembangunan masa depan. Perkembangan ini dilihat secara keseluruhan, perubahan perilaku wisatawan dan orang lokal berhubungan erat dengan peningkatan jumlah resort dan perluasan transportasi jaringan.

Lingkup wilayah dalam penelitian ini adalah seluruh desa di Kecamatan Borobudur, yaitu sebanyak 20 desa, antara lain : Desa Bigaran, Desa Borobudur, Desa Bumiharjo, Desa Candirejo, Desa Giripurno, Desa Giritengah, Desa Karanganyar, Desa Karangrejo, Desa Kebonsari, Desa Kembanglimus, Desa Kenalan, Desa Majaksingi, Desa Ngadiharjo, Desa Ngargogondo, Desa Sambeng, Desa Tanjungsari, Deas Tegalarum, Desa Tuksongo, Desa Wanurejo, dan Desa Wringinputih. 
Penelitian ini dilakukan dengan observasi lapangan, dengan melihat fenomena-fenomena yang terjadi pada lokasi penelitian dan mengamati subjek penelitian. Hasil observasi yang sudah didapat, diubah menjadi data digital. Responden dalam penelitian ini diambil menggunakan metode purposive sampling, yaitu teknik penentuan sampel dengan pertimbangan tertentu sehingga data yang diperoleh lebih representatif dengan melakukan proses penelitian yang kompeten dibidangnya (Sugiyono, 2009). Purposive sampling digunakan dalam penelitian ini untuk memperoleh data dari responden yang dianggap tahu (key informan) dan dapat memberikan data yang terpercaya. Responden utama dalam penelitian ini adalah warga masyarakat di desa sekitar Candi Borobudur.

Untuk memetakan tipologi desa sekitar Candi Borobudur berdasarkan potensi kepariwisataan dengan cara menganalisis temuan-temuan di lapangan kemudian dikompilasikan dengan teori maupun data lainnya. Pengidentifikasian dalam pengembangan potensi kepariwisataan dilakukan dengan cara observasi berdasarkan pada teori dan pengaruh lokal.

\section{Hasil dan pembahasan}

Tipologi desa-desa sekitar Candi Borobudur dipetakan berdasarkan potensi kepariwisataan dengan cara menganalisis temuan-temuan di lapangan berdasarkan fase dalam teori Miossec seperti dijabarkan pada Tabel 1 dan divisualisasikan pada Gambar 2.

Tabel 1. Tipologi desa di sekitar Candi Borobudur

\begin{tabular}{|c|c|c|c|c|c|c|c|}
\hline \multirow{2}{*}{ No. } & \multirow{2}{*}{ Nama Desa } & \multicolumn{4}{|c|}{ Penilaian Terhadap Aspek Miossec } & \multirow{2}{*}{$\begin{array}{c}\text { Hasil } \\
\text { Tipologi }\end{array}$} & \multirow{2}{*}{ Keterangan } \\
\hline & & Resort & Transport & Behaviour & Attitudes & & \\
\hline I. & Bigaran & $\mathrm{I}, 50$ & $2,7 \mathrm{I}$ & $I, 00$ & 2,00 & $\mathrm{I}, 80$ & \\
\hline 2. & Borobudur & 4.38 & 4,00 & 5,00 & 4,50 & 4,47 & \\
\hline 3. & Bumiharjo & 2,88 & 3,43 & 3,00 & 2,50 & 2,95 & \\
\hline 4. & Candirejo & 4,25 & 3,86 & 5,00 & 4,50 & 4,40 & \\
\hline 5. & Giripurno & 1,00 & $\mathrm{I}, 43$ & 1,00 & $\mathrm{I}, 75$ & $\mathrm{I}, 29$ & Tipe 1 Nilai $0,0-1,0=$ Tidak Berpengaruh \\
\hline 6. & Giritengah & 2,63 & $2, \mathrm{I} 4$ & 2,83 & 2,25 & 2,46 & Tipe 2 Nilai $1,1-2,0=$ Kurang Berpengaruh \\
\hline 7. & Karanganyar & 3,25 & 2,86 & 3,17 & 3,25 & 3,13 & Tipe 3 Nilai 2,1-3,0 = Berpengaruh Sedang \\
\hline 8. & Karangrejo & 3,38 & 3,00 & 3,33 & 3,75 & 3,36 & Tipe 4 Nilai $3,1-4,0=$ Cukup Berpengaruh \\
\hline 9. & Kebonsari & 3,13 & 2,43 & & 2,50 & 2,56 & Tipe 5 Nilai 4,1-5,0 = Sangat Berpengaruh \\
\hline I0. & Kembanglimus & 3,00 & 3,57 & 3,00 & 3,50 & 3,27 & \\
\hline II. & Kenalan & $\mathrm{I}, 38$ & 2,00 & 1,00 & $\mathrm{I}, 75$ & $\mathrm{I}, 53$ & \\
\hline $\mathrm{I} 2$. & Majaksingi & 4,38 & 3,29 & 4,17 & $\mathrm{I}, 75$ & 3,39 & \\
\hline I3. & Ngadiharjo & 2,88 & 2,43 & 2,17 & $\mathrm{I}, 75$ & $2,3 \mathrm{I}$ & \\
\hline I4. & Ngargogondo & 2,25 & 2,29 & $\mathrm{I}, 67$ & 2,50 & 2,I8 & \\
\hline I5. & Sambeng & $\mathrm{I}, 63$ & 3,00 & $\mathrm{I}, 50$ & 2,00 & 2,03 & \\
\hline I6. & Tanjungsari & $\mathrm{I}, 63$ & 3,29 & 2,00 & 2,75 & 2,42 & \\
\hline I7. & Tegalarum & 2,25 & 3,57 & 2,33 & 2,25 & 2,60 & \\
\hline I8. & Tuksongo & I,75 & 3,29 & $\mathrm{I}, 33$ & 2,50 & 2,22 & \\
\hline 19. & Wanurejo & 4,25 & 4,00 & 5,00 & 4,50 & 4,44 & \\
\hline 20. & Wringinputih & 3,75 & 3,71 & 4,00 & 4,25 & 3,93 & \\
\hline
\end{tabular}




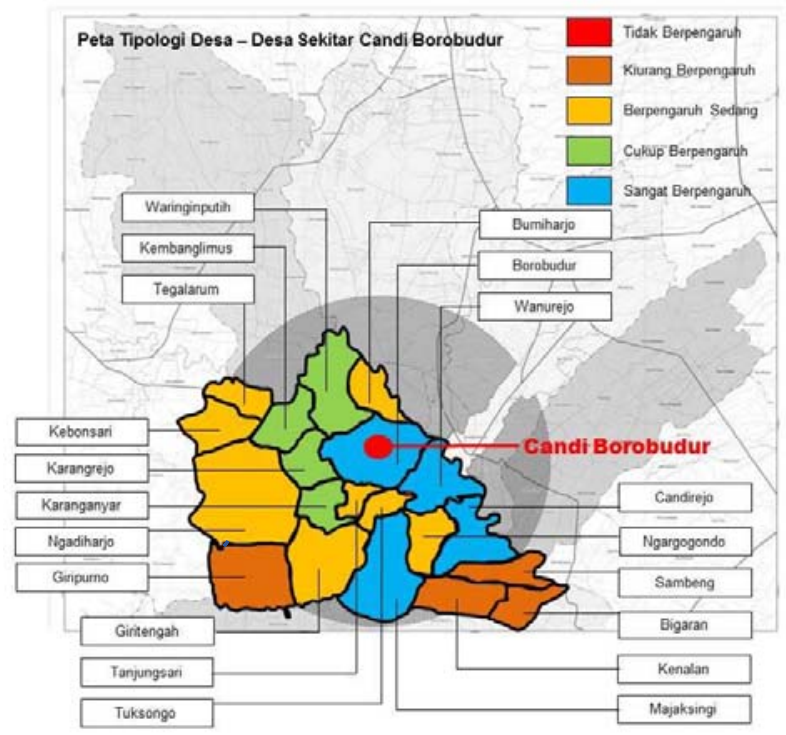

Gambar 2. Peta tipologi desa di sekitar Candi Borobudur

Berdasarkan hasil tipologi desa di sekitar Candi Borobudur (Tabel 1) dapat dijabarkan hasil penilaian tipologi desa di sekitar Candi Borobudur di bawah ini (Tabel 2).

Tabel 2. Penjabaran penilaian tipologi desa di sekitar Candi Borobudur

\begin{tabular}{|c|c|c|}
\hline $\begin{array}{c}\text { Hasil } \\
\text { Tipologi }\end{array}$ & Nama Desa & Keterangan Penilaian \\
\hline Tipe I & - & - \\
\hline Tipe 2 & $\begin{array}{ll}\text { I. } & \text { Bigaran } \\
\text { 2. } & \text { Giripurno } \\
\text { 3. } & \text { Kenalan } \\
\text { 4. } & \text { Sambeng }\end{array}$ & $\begin{array}{l}\text { Mulai ada pembangunan resort sebagai perintis. } \\
\text { - Wulai dibukanya jaringan transportasi. } \\
\text { wisatawan mulai memiliki informasi / persepsi secara global mengenai daerah tujuan } \\
\text { Kebijakan pemerintah dan tanggapan masyarakat masih terbatas pada tahap pengamatan } \\
\text { (observasi) }\end{array}$ \\
\hline Tipe 3 & $\begin{array}{ll}\text { 5. } & \text { Bumiharjo } \\
\text { 6. } & \text { Giritengah } \\
\text { 7. } & \text { Kebonsari } \\
\text { 8. Ngadiharjo } \\
\text { 9. Ngargogondo } \\
\text { I0. Tanjungsari } \\
\text { 11. Tegalarum } \\
\text { I2. } & \text { Tuksongo } \\
\end{array}$ & $\begin{array}{l}\text { Keberhasilan resort wisata perintis mempengaruhi perkembangan dan pembangunan fisik } \\
\text { di dalam kawasan serta bagaian lain dari kawasan dalam tahap selanjutnya (keseragaman } \\
\text { resort). } \\
\text { - } \quad \text { Bertambahnya jaringan transportasi yang menghubungkan antar resort. } \\
\text { - Semakin meningkatnya persepsi wisatawan terhadap daerah tujuan wisata dan perjalanan } \\
\text { wisata. } \\
\text { - Adanya kebijakan pemerintah di bidang infrastruktur yang melayani kawasan tersebut. }\end{array}$ \\
\hline Tipe 4 & $\begin{array}{ll}\text { I3. } & \text { Karanganyar } \\
\text { I4. } & \text { Karangrejo } \\
\text { I5. } & \text { Kembanglimus } \\
\text { I6. } & \text { Wringinputih }\end{array}$ & $\begin{array}{l}\text { - } \quad \text { Resort mulai terorganisir dan memiliki hirarki. } \\
\text { - } \quad \text { Mulai tersusunnya rute perjalanan wisata. } \\
\text { - } \quad \text { Bertambahya persaingan tempat dan terjadi pemisahan - pemisahan. } \\
\quad \text { wisatawan dan kegiatan pariwisata oleh penduduk lokal. }\end{array}$ \\
\hline Tipe 5 & $\begin{array}{ll}\text { I7. } & \text { Borobudur } \\
\text { I8. } & \text { Candirejo } \\
\text { 19. } & \text { Majaksingi } \\
\text { 20. } & \text { Wanurejo }\end{array}$ & $\begin{array}{l}\text { - Resort telah memiliki spesialisasi dan hirarki yang jelas. } \\
\text { - Jaringan transportasi dari tingkat keterhubungan dalam wilayah mencapai titik maksimal. } \\
\text { - Mulai diterapkannya kontrol perencanaan, dan mulai terbentuk dan berkembang jenis - } \\
\text { - jenis wisata tertentu. } \\
\text { - Spesialisasi kawasan sesuai kapasitas dan daya tarik bagi kawasan. }\end{array}$ \\
\hline
\end{tabular}

\section{Simpulan}

Dalam kesimpulan ini berisi resume dari analisis dan pembahasan. Desa sekitar Candi Borobudur memiliki tipologi potensi yang berbeda - beda, setelah melakukan survei dengan cara observasi, wawancara dan data sekunder kemudian penulis menganalisis menggunakan Teori Miossec dan sub sub teori terkait, maka desa - desa sekitar Candi Borobudur digolongkan menjadi 5 tipe, yaitu tipe 1 tipe 5. Tipe 1 adalah desa yang tidak berpengaruh terhadap pariwisata, tipe 2 adalah desa yang kurang 
berpengaruh terhadap pariwisata, tipe 3 adalah desa yang berpengaruh sedang terhadap pariwisata, tipe 4 adalah desa yang cukup berpengaruh terhadap pariwisata, dan tipe 5 adalah desa yang sangat berpengaruh terhadap pariwisata.

\section{Referensi}

- Pearce, D. G. (1989). Tourist Development. Longman Scientific \& Technical.

- Sugiyono. (2009). Metode penelitian kuantitatif, kualitatif dan R \& D. Penerbit Alfabeta 